\title{
Compliance/Adherence, HIV, and the Critique of Medical Power
}

\author{
ERIC MYKHALOVSKIY ${ }^{1}$, LIZA MCCOY ${ }^{2}$, MICHAEL BRESALIER ${ }^{3}$ \\ ${ }^{1}$ York University, 0N, Canada. E-mail: ericm@yorku.ca \\ ${ }^{2}$ University of Calgary, Calgary, Canada. E-mail: mccoy@ucalgary.ca \\ ${ }^{3}$ Cambridge University, Cambridge, UK. E-mail: mcb37@cam.ac.uk
}

\begin{abstract}
The established social critique of compliance was written in the late 1970s and early 1980 s by a group of sociologists and anthropologists. Drawing on a humanist perspective, it argued that compliance operated as a form of medical control over patients that ignored their experiences of medications or defined them in terms of professional expectations. In this paper we draw on the theoretical work of Smith and Foucault and on original research on the 'healthwork' of people living with HIV/ AIDS to revise this critique. Our analysis foregrounds the heterogeneity of power relations exercised through contemporary relations of compliance/adherence. We argue that in the contemporary context of HIV/AIDS, compliance/adherence operates as a fundamental discursive ground of people's healthwork and is constitutive of, rather than hostile to, experience and the self. Considered as a technology rather than concept, adherence groups together a host of strategies designed to cultivate a particular relation of self to treatment in ways that do not operate with the uniform force suggested by the early social critique. At the same time, compliance is not simply about liberal forms of self-governance. It is a site where multiple forms of power - biomedical authority, population-based forms of risk governance, and liberal techniques of the self - intersect in relations of tension, negotiation, and support.
\end{abstract}

Social Theory \& Health (2004) 2, 315-340. doi:10.1057/palgrave.sth.8700037

Keywords: compliance; adherence; HIV; biomedicine; treatments; power

I remember the first night of laying out the medications, like putting them in the dosette and then the first morning of taking them was just, it was scary because, it's this whole piece around faith and hope, pinning my hopes on whether these pills would do what they were supposed to do. And realizing that the first time I took the pills that this was not something that I was going to be 
doing for a week, or two weeks, but basically until further notice. This was going to be a part of my life.

(IN 17). ${ }^{1}$

\section{INTRODUCTION}

This paper explores the problematic of adherence, widely understood to be a matter of how well patients follow health advice. In the paper, we pose questions about how adherence and the related term compliance have been sociologically conceptualized and draw on recent developments in HIV/AIDS to suggest new possibilities. Our paper seeks to reinvigorate a social critique of compliance that continues to shape thought about medication use but that has not been widely updated, despite new developments in the social study of health and illness and important recent changes in health care and the health sciences.

The established social critique of medication compliance was written in the late 1970s and early 1980s. It was analytically organized as a humanist critique of medical dominance. In general, the early social critics understood adherence or compliance, the more popular term at the time, as a form of medical control. They were concerned about how a biomedical perspective on compliance ignored patients' experiences of medications or defined them in terms of professional expectations and set out to reorient its objectifying features in their own empirical research.

In this paper, we aim to revise a sociology of compliance preoccupied by a critique of an antihumanist medicine. We argue that the established social critique fails to make sense of the current complexity and heterogeneity of power relations (Weir, 2004) exercised through compliance/adherence. In its place, we recommend a critical practice concerned with the interplay of various forms of power - both limiting and productive - that attach to adherence across and through multiple sites: medicine, public health, AIDS service organizations, and people living with HIV/AIDS (PHAs).

Our argument is based on reflections from our recent ethnographic research on the 'healthwork' of people living with HIV/AIDS (Mykhalovskiy and McCoy, 2002). In the West, the representation, medical care, and experience of HIV infection have been transformed by the introduction of new forms of combination drug therapy collectively referred to as highly active antiretroviral therapy or HAART. HAART regimens typically combine three or more types of antiretroviral treatment. While from a biomedical perspective they offer increased activity against HIV, they can be difficult for people to take and have strict compliance requirements. In our research, we sought to 
explore the social, discursive and institutional context within which people living with HIV/AIDS 'look after' or 'do' their health, especially as it involves connections with newly available biomedical treatments. In pursuing that goal we have been mindful of the unique context of AIDS treatment activism that has shaped the healthwork of PHAs, in part by helping to make HAART possible.

In seeking to reorient the sociological critique of compliance, we take inspiration from recent work that investigates biomedicine as a multiple and variegated domain of practice (Mol, 2002; Mol and Berg, 1998; Clarke et al., 2003, Löwy, 1996; Weir, 2004). From a theoretical location dually informed by Smith (1987, 1990, 1999) and Foucault (1980a [1976], 1980b [1976], 1994 [1963]) we build on that work by focusing on the multiple forms of power with which medicine is implicated at the site of adherence. Smith's work is an empirical sociology of 'ruling relations' focused on the operation of textmediated forms of discourse. Her work has been drawn upon in a number of studies exploring the organization of health services including the operation of health policy and biomedical discourses (Smith, 1995; Mykhalovskiy, 2003; Campbell et al., 1998; Rankin, 2001). Foucault's notion of governmentality (1991) has given rise to a historically oriented literature emphasizing the productivity of expertise and the centrality of the 'self' in contemporary forms of governance (Miller and Rose, 1990; Burchell et al., 1991; Cruikshank, 1999; Rose, 1999).

While Smith's project and Foucauldian work each has its own intellectual specificity, we draw them together as resources that help us to think about power as multiply sited and exercised through relations of knowledge. From this location, our analysis of interviews with people living with HIV, community-based HIV health information and the current biomedical research literature suggests that in the context of HIV much more is at work in people's relationships to treatments and medical advice than the power of medicine over patients.

In developing our analysis, we acknowledge recent changes in health sciences discourse. From the late 1970s onward, the term adherence has been popularized within biomedicine as a less paternalistic alternative to compliance and is now the preferred term. This switch in terminology reflects an accommodation of the early social critique of compliance. At the same time, in our research we found both concepts used interchangeably to reference contemporary medication practices. ${ }^{2}$

In this paper, we argue that in the contemporary context, adherence and compliance do not operate as biomedical concepts grounding an oppressive medicine that eschews the phenomenal realm of 'patient experience.' Compliance/adherence has a much broader social presence and is not fully 
counterposed to experience. We suggest that compliance/adherence operates as a fundamental discursive ground of people's healthwork and is constitutive of experience and the self. Adherence further operates as a social technology tied not only to biomedicine but to other sites including, most importantly, AIDS service organizations and the apparatus of public health. Considered as technology rather than concept, adherence groups together a host of strategies designed to cultivate a particular relation of self to treatment in ways that do not operate with the uniform force and domination suggested by the early sociological work. At the same time, compliance is not simply about liberal forms of self-governance. It is a site where multiple forms of power - biomedical authority, population-based forms of risk governance, and liberal techniques of the self - intersect in relations of tension, negotiation, and support.

\section{THE ESTABLISHED SOCIAL CRITIQUE OF COMPLIANCE}

The foundational texts in the social investigation of medication compliance were published in the 1970s and 1980s by Zola (1981), Stimson (1974), Conrad (1985) and Trostle (1988; Trostle et al., 1983). While this formative work is varied, encompassing commentary, review of the biomedical literature, historical work, and original empirical research on 'patient' experiences, it has an internal analytic coherence as humanist antimedical critique.

This form of critique typically conjoins two related moves: (1) a rebuke of medical encroachment on or negation of the 'social,' with particular concern for medical control over the patient and (2) efforts to recuperate the phenomenal realm of patient experience. Those who have posed questions about the possibilities and limitations of the humanist social critique of biomedicine have been primarily concerned with its use in research on medicalization. For example, in an important early statement, Strong (1979) called for greater reflexivity on the part of sociological critics of medicalization, arguing that they had failed to acknowledge the self-interested character of their critique of medical power. Writing from a Foucauldian perspective Osborne (1994, p. 37) suggests that the critique of medicalization fails to recognize how clinical medicine 'is constitutive of the modern experience of individuality. Arguments about unwarranted medical authority and the erasure of the patient have also found fertile ground in sociological work on compliance. Here, the primary concern has been with compliance as an invention of biomedical research. A central argument has been that the compliance literature limits thought about people's relationships with treatments by underscoring authority relations and narrow physician relevancies. 
Conrad (1985), for example, suggests that compliance reflects a 'doctorcentred' perspective that unduly privileges questions about how well patients follow medical advice over other forms of experience with treatments. Stimson (1974, p. 102) also argues that compliance studies reflect the 'point of view doctors.' In his view, they construct a terrain in which the complexity of patients' behaviour is obscured by research narrowly focused on why 'people fail to follow doctor's instructions' (1974, p. 99). In his important article 'Medical compliance as an ideology', Trostle (1988) adds to these arguments. Drawing on historical research, he argues that 'compliance is an ideology that transforms physicians' theories about the proper behavior of patients into a series of research strategies, research results and potentially coercive interventions that appear appropriate, and that reinforce physician's authority over health care' (Trostle, 1988, p. 300).

The humanist sociological critique of compliance generally understands medical power in terms of negation and oppression. It draws on a 'negative theory of power' (Foucault, 1980a), one that focuses on how power shuts down, restricts and excludes. Thus, Zola and colleagues are concerned with how biomedical research on compliance objectifies patients and narrowly delimits the scope of their actions. They take issue with how non-compliance and its related terms - defaulting, refusal, deviation, failure to cooperate and disobedience - position patients as aberrant. They further suggest that compliance research reduces patients to passive recipients of medical instructions, neglects aspects of their lives and experiences that transcend the biomedical milieu, and treats their departures from medical norms and expectations as irrational.

As a corrective, they put forward a humanist analytic that counters biomedicine by articulating a 'patient-centred' perspective on compliance. In one version advocated by Zola (1981), the goal is to humanize doctor-patient interaction. Zola wants to turn the established object of compliance research on its head by focusing on the role that practitioners, rather than patients, play in contributing to non-compliance. He argues that patients fail to comply with medical advice because they are poorly treated and disempowered in medical encounters. The solution, in his view, is to strengthen the position of the patient in the medical consult and reorient compliance research to address troubling features of medical interaction that hinder compliance.

Others seek to more radically decenter medical perspectives on noncompliance. They argue that biomedical research overemphasizes the role that the doctor-patient relationship plays in compliance and turn to events, processes and activities occurring outside the clinic to formulate an alternative. Conrad (1985), for example, develops the notion of 'medication practice' as a way to more fully explore patients' active engagement with 
medications than the established compliance research allows. Drawing on research involving epileptics, he argues that the meanings patients create about medications, including feelings of dependence and stigtmatization, better explain divergences from medical instruction than internal features of the doctor-patient relationship.

Stimson's (1974) efforts take a slightly different turn in their focus on placing patients' experiences of illness and taking medications in their 'social context.' In his view, patients do not passively follow medical advice as given. They evaluate doctors' recommendations and make their own decisions on the basis of ideas and experiences to do with medications that circulate among family members and friends outside the immediate medical setting. Trostle et al. (1983) try to undo the characteristic emphasis of compliance research by developing an analysis of 'medication management activities' from 'the perspective of patients.' In an argument extended in later social research on compliance/adherence (eg Donovan and Blake, 1992; Hunt and Arar, 2001; Hunt et al., 1989: Chewning and Sleath, 1996; Lerner et al., 1998) they claim that what appears as non-compliance from a medical perspective emerges as reasonable activity when viewed from the context of patients' everyday lives.

The early humanist critique of compliance was vital to sociology's efforts to reframe its relationship to biomedicine. The work of Conrad, Zola and others on compliance was part of a broad effort to recast what had been a 'sociology for medicine' as an independent analytic project. No longer contained by the imperatives of biomedicine, a revitalized sociology would treat medicine as an object of critique, explore its dangers, and move to investigate the variety and complexity of patients' experiences and the broad social character of health and illness. The humanist critique of compliance contributed to this renewal by exposing the normative dimensions of medical power. It destabilized presumptions of medical neutrality, revealing compliance to be a deeply troubled concept that projects relations of obedience and treats as problematic human activity that falls outside of professional medical expectations. At the same time, the critique contributed in enduring ways to the sociological project of investigating the experiences of people living with chronic illnesses. The early critique of compliance stimulated research on doctor-patient interaction, on the meanings of medications and opened up new ways to think about the relationship between people and medical treatments.

\section{A CRITIQUE OF THE CRITIQUE}

Yet the established sociological analysis of adherence also had limitations. Posing questions about them is a task complicated by the problem of 
hindsight. We do not wish to stand in judgement of the literature for not anticipating current developments. Rather, our concern is to consider its contemporary purchase. Some 20 years after its making, how does the mode of analysis developed by the early sociological critics of compliance fare? Which features of the critique of medical power they made maintain their salience? Which might benefit from revision?

We treat HIV/AIDS as an empirical terrain for exploring these questions and draw specifically on the results of our own research on the experiences that people living with HIV/AIDS have of taking complex drug regimens (Making Care Visible Project Team, 2002; Mykhalovskiy and McCoy, 2002). Our central argument is that the claim that medicine operates as a negative power effacing patient experience (Mykhalovskiy and Weir, 2004) can make only limited sense of compliance/adherence in the current context. Within contemporary relations of adherence multiple forms of power are at work creating tensions, alignments and disjunctures between biomedicine, public health and a politics of life (Rose, 2001) that is constitutive of human subjectivity. Understanding the contemporary politics of adherence necessitates a move beyond antimedicine. Before turning to our central argument, we offer some brief comments on problems internal to the critique of compliance as initially developed by its proponents.

First, in our view, the early sociological literature fails to give sufficient attention to the interdiscursive constitution of compliance. Zola, Stimson, Conrad and Trostle all treat compliance as a medical concept. They name its specificity by citing a definition initially formulated by Sackett and Haynes in 1976 and modified in 1979; 'compliance (is) the extent to which a person's behaviour (in terms of taking medications, following diets, or executing lifestyle changes) coincides with medical or health advice.' (Haynes et al., 1979 , p. xv). That definition is mobilized throughout the sociological literature as a warrant for a critique of power focused almost exclusively on biomedical authority over patients.

The problem with this analytic strategy is that it obscures the important role that public health authorities, operating at the edges of clinical medicine, played in the early formulation and promotion of compliance/adherence (Lerner, 1996). It is also the case that sociology itself is deeply implicated in conceptualizations of compliance. One need look no further than Parsons' (1951) infamous 'sick role' to find a potent source of thinking that formulates a normative relation between ill people and the requirement to follow medical advice. Compliance/adherence, then, has multiple discursive sources. While the early critics were likely aware of this multiplicity, it did not figure in their analysis, a problem that reflects the limits of a univocal critique of medical power. 
On a related point, we suggest that the early social commentary fails to sufficiently register the internal complexity and heterogeneity of the biomedical concept of compliance, even as the concept was being expressed at the time. The early critique did expose the limits of a conceptual project focused on patients' cooperation with medical advice and the search for socio-demographic variables that disrupt it. But biomedical research on compliance has never been as hermetic as the social critique implies. For example, the two formative edited volumes on compliance published in the 1970s include contributions that expose the equivocal results of efforts to associate non-compliance with established socio-demographic characteristics (Hulka, 1979; Haynes, 1979a). They also explicitly identify medical practitioners as implicated in patient non-compliance and at least recognize the concept's power effects in their efforts to popularize the putatively less paternalistic term adherence (Haynes, 1979b). This 'generous' reading of the biomedical compliance literature is not an expression of political naivety, but an attempt on our part to register immanent tensions within the concept of compliance that its treatment as the monolithic erasure of the patient misses.

Finally, and most problematically in our view, the early sociological work on compliance is trapped by the object of its critique. The work of Zola, Conrad and others expresses the ambivalences of sociology's then relationship to biomedicine. For even as it critiques the 'biomedical perspective' on compliance for denuding human experience, even as it seeks to decenter biomedicine, and to make a place for an independent sociology, it carries forward key features of the conceptual and programmatic project of biomedical research on compliance.

Zola and colleagues are not simply crude advocates of anti-medicine. While they have harsh words for biomedicine and are highly critical of medical authority over patients, they equally hope to reform biomedicine by making it more responsive to the life world. Sociology is thus cast in a dual role as critic and saviour. It denounces the excesses of biomedical objectification but also seeks to humanize it by making visible patients' experiences and the social factors shaping them. In the end, this posture does not so much trump biomedicine as establish a field of expertise on patient meanings that claims to better illuminate the reasons behind non-compliance than biomedicine. The analytic shift envisioned by a turn to 'patients' definitions of the situation' does not fundamentally reformulate the established problematic of biomedical compliance research. For the structuring effects of that research take hold in the sociological critique through a continued emphasis on deviance - on those who do not comply. What is different is not so much the object of study (non-compliance) but what gets used to explain it: the social. 


\section{COMPLIANCE REVISITED: THE CONCEPT OF HEALTHWORK}

Our experience of conducting research on the healthwork of people living with HIV is central to our efforts to think through new possibilities for the sociological critique of compliance and medical power. Our research began in 1998 at a time when highly active antiretroviral therapy was emerging as the cornerstone of medical care for HIV infection in the West. HAART, as the treatments are called, involves combining antiretroviral drugs that attack the cycle of HIV replication in different ways, thus offering a more potent offence against the virus than is possible through monotherapy (Volberding, 2003; Wynn et al., 2004).

HAART has provoked a number of transformations in how HIV is lived and represented. The treatments have resulted in declines in mortality and morbidity among people living with HIV, helping to occasion a reframing of HIV disease as a chronic, manageable infection (Palella et al., 1998; Murphy et al., 2001; Bartlett, 2002). Under conditions of HAART, people living with HIV are expected to undertake a significant reorganization of their daily lives around medication schedules. The regimen complexity and pill burden of HAART can be extremely high (Chesney, 2003), the commitment to therapy is ongoing, and the burden of side effects can be heavy (Highleyman, 2000). Recent biomedical research argues that the therapeutic effects of HAART are contingent upon it being taken exactly as prescribed (Paterson et al., 2000; Bansberg et al., 2000). The strict adherence requirements of the treatments and the activities of a powerful patient-based movement make HIV/AIDS an interesting site for exploring the contemporary politics of adherence.

Our research on the healthwork of people living with HIV was informed by the turn to patient experiences advocated by the early social critics. We too wanted to begin with the experiences that people with chronic illness have of medications. We were concened by the notion that the compliance literature restricts the actions of patients to following medical orders. Like Conrad, Zola and others, we were committed to bringing into view the fuller range and complexity of activities through which people engage with medications.

We were aided in that task by our use of the concept of healthwork (Mykhalovskiy and McCoy, 2002). By healthwork, we mean the broad terrain of everyday/everynight activities through which people look after their health. We use the term not to prefigure the normative grounds of health practice, but to gesture to a wide range of health activities whose precise content is not known in advance of investigation. The term has much in common with Conrad's notion of medication practice. ${ }^{3}$ Unlike Conrad, however, we were less concerned with the realm of patient 'meanings' than with people's purposeful day-to-day activities. The primary question we 
asked was 'how do people do medications?' not 'what do medications mean to them?' We were also not explicitly concerned to contribute to the project of improving compliance. We did not ask about people's non-compliance with HAART, nor did we treat the social as a terrain for identifying its sources.

The concept of healthwork also departs from the term 'work' as deployed by Corbin and Strauss $(1985,1988)$ in their effort to develop a grounded social-psychological theory of chronic illness. They use the concept to theorize the trajectory of chronic illness as a process that involves an interaction between biological disease progression and an ongoing interrelationship and negotiation of various forms of work (biographical, illnessrelated, and everyday life work) that sufferers and their spouses undertake in their daily lives. Our own concept of healthwork is not used as part of a theory-building exercise. Rather it coordinates an ethnographic project that commits analysis to exploring how people's experiences, in this case their experiences of taking HAART, are socially organized through large-scale forms of coordination that 'hook' individuals into extended relations of governance and ruling. We set out to learn from people living with HIV about how they look after their health and take HAART as those activities take shape within a complex of institutional relations involving such sites as doctors' offices, hospitals, AIDS service organizations (ASOs), pharmacies, social service agencies, the pharmaceutical industry and the forms of biomedical and other discourses that interpenetrate them.

Our inquiry involved individual and focus group interviews with 79 people from varied social locations living with HIV/AIDS in and around Toronto as well as an examination of the health information activities of Toronto-based ASOs and a review of the recent health sciences literature on HAART and adherence.

We asked participants what it was like being on HAART and in response heard a range of accounts in which participants located taking medication within a field of other projects and relevancies and evaluated the success of the drugs using alternate, non-biomedical forms of rationality, for example: 'I did take it [HAART] and it didn't agree with me... [I was] moody, cranky ... didn't want to be around people... I couldn't handle it, so I just took myself off of it.' We heard from participants how they reinterpreted medication instructions to fit the regimen to their life and were reminded that people value sources of knowledge other than medical authority: 'I take AZT three times a day, that is the prescribed dosage. Then I find out that you can actually take the six pills twice a day - so so three and three rather than two, two, and two. This is not coming from the medical profession... the [PHA] community is saying that you don't have to take them that way.' We also heard extensive descriptions about the daily forms of 
work - organizational, emotional - that go into achieving adherence and creating the conditions for successful pill taking. Our findings thus echo in many respects the findings and analyses of earlier researchers who emphasized the active work, complex relevancies and diverse rationalities that characterize people's participation in pharmaceutical treatment for chronic illness.

\section{COMPLIANCE AND EXPERIENCE}

However, our research also differs from the earlier literature. Rather than supporting an understanding of compliance as an internal concept of biomedicine fully hostile to experience, our research suggests that compliance/adherence discourse has a broad and active social presence in the dayto-day lives and experiences of people living with HIV.

The participants in our study drew actively and widely on compliance/ adherence perspectives as a narrative framework for thinking and talking about themselves in relation to HAART. This is not the only way they spoke about medications. Narratives of embodiment focused on bouts of dizzying nausea, vomiting, diarrhea, and extreme fatigue that came with taking pills were particularly common. But in light of the sociological critique we were particularly struck by how compliance/adherence operated as a common interpretive frame through which people expressed their relationship to treatments. Here are two short examples:

Overall, my attitude about compliance is that everything I do is, of course, mandatory. There is no other avenue I would consider.

I: Was it difficult for you to be that compliant?

No. No. I love organization and I consider this, without being melodramatic, unquestionably the biggest challenge of my life. And that's to stay alive. So, I've got to do everything, throw everything I can, and nothing must get in my way (IN 9).

Everything that I've read says that it's not good to miss a dose because then you become resistant to the drugs... But I thought, 'I'm not going to sit there and worry abut it'. I've been pretty lucky so far and my regime has been, I haven't really altered it. And every once in a while, like once in a blue moon, I wake up... Let's say I have to take my dose at one o'clock in the morning. So let's say I take it at five, I have to take it at one. 'cause I usually take it between seven and nine hours later. And I missed it, you know, I wake up at three o'clock and I thought 'I'm not getting out of bed to take some pill.' (FG 1).

As these quotes suggest, people living with HIV in our study oriented to compliance/adherence in different ways. Some described themselves as 
highly compliant with pill regimens, others clearly did not. For many people we interviewed, achieving adherence was a goal and almost all participants in some way made sense of their medication practices in light of adherence demands and requirements. But this should not be taken as evidence of the biomedical colonization of experience. Even those who took up a heavy compliance frame never simply parroted biomedical discourses or talked in ways that suggested the actions of pure biomedical subjects. Rather, their narratives of healthwork pointed to the complex and creative interplay between biomedical and other ways of knowing (see also Rapp, 2000; Root and Brownher, 2001; Moore et al., 2001).

For example, those who described their medication practices as closely aligned with idealized medical instructions often did so as part of broader narratives of healthwork organized by what we call the 'good PHA' discourse. The good PHA discourse is a normative discourse produced out of the activities of AIDS service organizations. It combines a politics of community empowerment with health consumerism in the figure of the assertive person with HIV. The good PHA is not simply a compliant patient, he or she is a knowledgeable health consumer and active community member who takes responsibility for his/her health, is well-connected with PHA networks, keeps up to date with treatment information, makes informed decisions, and takes medications as prescribed.

Other participants drew on the language of compliance/adherence to describe their experiences of pill-taking in ways that were densely mediated by contemporary psy discourses. For them, being 'adherent' was not a matter of yielding to medical authority, but of overcoming emotional and physical resistance to a difficult regimen by expanding self-knowledge and developing forms of self-management. People often described this healthwork through narratives of before and after, in which earlier periods of anger, resistance and missed doses gave way to periods of greater stability, emotional or spiritual strength and 'compliance'.

I was in a hectic relationship for years and I left that guy and I have been in a stable relationship for over three years now. The first year and a half I had lots of problems to work out. A drug habit to kick and an alcohol problem and well, in the last two years it has been getting better and this last two years have been excellent. I do not have, since I started on 3TC and whatever, I do not have problems because I do not have a drug habit and I am not hung over half the time. Because taking the meds with alcohol is very hard and I found that out the hard way (FG 12).

Rather than expressing the biomedical objectification of experience, accounts such as the one above suggest how notions of compliance/adherence have 
been incorporated into projects of realizing 'the self' (Crawford, 1994). Many PHAs in our research expressed genuine feelings of empowerment, satisfaction and pride when they talked about 'becoming' compliant. In their narratives, compliance/adherence appears not as disruptive of experience, but as a practice they actively seek to create and whose accomplishment marks a new way of speaking 'the self.' That such tellings were mediated by psy discourses of self-improvement indicate the need to revise an analysis that frames the relationship of experience and compliance within a dynamic of medical objectification or negation. In our research, compliance/adherence grafts onto and commingles with other discourses, preoccupations, and forms of reasoning and has a more constitutive relationship to experience than the early critique allows for.

\section{COMPLIANCE/ADHERENCE: FROM BIOMEDICAL CONCEPT TO SOCIAL TECHNOLOGY}

The prevalence and variety of compliance/adherence talk in people's narratives of healthwork further suggest that compliance/adherence might now be better understood as a heterogeneous discourse with multiple sites of production and distribution than as an exclusive concept of biomedicine. In his work on contemporary forms of government, Rose (1994) argues that expertise does not operate through exclusion, but through the social proliferation of expert vocabularies and concepts. Our textual research certainly supports this way of thinking about the contemporary discursive mechanics of compliance/adherence.

Adherence has always been a concern of HIV care, even in the days of AZT monotherapy. But after 1996, when combinations of different classes of antiretroviral drugs emerged as a viable treatment option in developed nations, adherence considerations began to explode. Driven partly by biomedical research arguing that the therapeutic value of HAART relies on treatments being taken exactly as prescribed, compliance quickly emerged as a focal point in various sites beyond medicine proper.

One important source of thought about adherence has been the 'allied' health professions. Nursing and social work, in particular, have developed literatures that constitute adherence to HAART as an 'extra-medical' problem, one amenable to their specific forms of expert intervention (Linsk and Keigher, 1997; Holzemer et al., 2000; Cox, 2002; Dilorio et al., 2003). A typical point of emphasis is the value that multidisciplinary, team-based support and counselling can have for improving patient compliance (Mundy et al., 2002) Adherence has also emerged as a ground for making marketing claims about 
pharmaceutical drugs (Rosengarten, 2004). With the consolidation of new HIV treatment options, pharmaceutical companies have moved quickly to establish compliance considerations as a basis of consumer and physician choice. Here, adherence is rendered a property of a given treatment, with information drawing attention to selling features of particular product lines. For example, the anti-HIV treatment SUSTIVA, manufactured by Bristol-Myers Squibb (2004), has been aggressively marketed on the basis of its once a day regimen. Product information for the drug proclaims 'one pill, simple dosing, helps promote compliance' while a Bristol-Myers website invites PHAs to take a readiness quiz to answer whether 'once-a day therapy [is] right for me' (www.bmsvirology.com/managehiv).

AIDS service organizations have also become extremely important sites for the production of knowledge about compliance to HAART. Through the publication activities of ASOs, a critique of adherence requirements that calls for simpler drug regimens has emerged. In addition, the health education activities of ASOs have created conditions for the emergence of communityoriented, experiential forms of knowledge about adherence. The websites, publications, treatment information phone lines and other services provided by ASOs, are not simply vehicles for translating biomedical information to lay audiences. They conjoin that information with the accumulated practical wisdom that people living with HIV have of taking HAART. Creating and sharing advice stories about using pill beepers, adjusting daily life rhythms to keep on track with complicated treatment regimens and so on, registers adherence within the embodied practices of PHAs, helping to constitute it as an embodied collective practice and realizable goal of the 'good PHA'.

In the current context of HIV, then, compliance/adherence can no longer be understood to have a primary social presence as medical ideology. These concepts are not a preserve of biomedical thought, but are spatially and discursively diffuse. Rather than operating as a form of external medical control over patients, adherence might be better viewed as a complex social technology, one in which ideas and practical strategies for self-management - from electronic pill dispensers, to pharmaceutical innovations, to memory aides and counselling strategies - intersect across a variety of interlocking sites.

\section{COMPLIANCE/ADHERENCE AND THE HETEROGENEITY OF POWER RELATIONS}

These multiple institutional sites of production and realization of compliance/adherence discourse and strategies embed contemporary relations of adherence within multiple forms of power. Recent work by Weir (2004) has 
emphasized the heterogeneity of power forms codeployed in health: sovereign, disciplinary and governmental. By stressing the heterogeneity of power within adherence, we do not mean to suggest that medical power is not exercised over patients, that all is well and good in biomedicine. In our interviews we heard many troubling accounts from PHAs about feeling pressured or compelled by physicians to take HAART.

That is the same thing with my doctor... He suggested right away that I take the cocktail. 'I do not think so.' He made me feel like I was going to get sick right away (FG 3).

I felt like she said when she mentioned that she was forced into making a decision. That is why I felt that I didn't last more than six months taking HAART. Between my G.P. and specialist, both of them, ganging up on me saying 'Take this, take this,'... that kind of crap scared me (FG 9).

People's accounts of having their concerns about HAART overruled by strict medical instruction point to the enduring presence of forms of medical exclusion and objectification that animated the early sociological critique of compliance. Yet biomedicine is not simply a vehicle of negation. Nor does it operate in isolation. It is implicated in other forms of power that are sourced in and expressed through related institutional sites. These include, most importantly, population-based forms of risk governance tied historically to public health discourses and practices and liberal forms of power through which people with HIV govern themselves in the name of better health, a project increasingly facilitated by the activities of ASOs.

Most of our research participants who spoke about taking HAART as a matter involving medical compulsion were from marginalized social and economic backgrounds. Their treatment as people whose relationship to medications is potentially suspect and who thus require particularly zealous or emphatic medical advice expresses a form of power exercised through processes of subjectification based on adherence possibilities. In the early days of HAART, some public health authorities and physicians argued that combination therapy should be withheld from disadvantaged PHAs injection drug users, racial minorities, homeless people and people with mental illness - because they were understood to be unable to manage complex drug regimens (Senak, 1997; Sollitto et al., 2001).

These arguments were not typically made from the standpoint of clinical reasoning and concern for individual optimization of health. Rather, they were framed within a public health logic of risk management preoccupied with securing the health of the general population. As the reasoning went, certain categories of people could not be trusted to take their 
medication as required. Their non-compliance would result in viral replication in the body and, along with it, alterations in the genetic structure of HIV that would release drug resistant strains of virus into the population when non-adherent HAART users engaged in high risk activities (Wainberg and Friedland, 1998).

Physicians enter the circuitry of population-based risk politics by unfairly denying treatment to PHAs. In so doing they do not simply exert medical control over patients. They put in motion a specific form of subjectification that links presumed incapacities of patients with stereotypes associated with particular disadvantaged groups. This has historical roots in early public health movements. Historian Baron Lerner (1997) has written about emerging forms of public health classifications applied to people who disobeyed 20th tuberculosis prevention efforts. In his view, current practices that associate non-adherence to HAART with disadvantaged PHAs are historically linked with the activities of early public health reformers who described those who did not follow anti-TB measures as 'alcoholic men' or 'derelicts' who were 'dangerous,' 'ignorant' or 'recalcitrant.'

Adherence, then, is an important site through which biomedicine becomes part of a population-based politics of risk management. Contemporary relations of power in compliance now include various forms of 'biopower' (Foucault, 1980a [1976]) - an organization of power that seeks to optimize the health of populations. HIV has long been a terrain upon which individuals have been construed as threats to the health of the general population. Adherence extends those concerns to the introduction of new drug-resistant forms of HIV into the population. Biomedicine is certainly bound up with the exercise of adherence-based forms of subjectification that would govern the health of populations, but its primary expression is in practices of public health and epidemiology.

In our interview research, we did not hear many accounts from PHAs about having medication denied to them by physicians. We did, however, hear about the operation of the more traditional police powers of public health. These accounts came primarily from PHAs who were living under conditions of social and economic marginalization. One man - a Black Canadian living in prison - told of being required to take medication by probation order. Another PHA told about how he began taking HAART after coming to the attention of the public health department which had the authority to require him to treat his HIV:

I went to donate blood and passed the preliminary and it was two weeks later the public health department contacted me and they informed me (about HIV + status). I openly, honestly admitted that I knew and went and donated 
blood. So right then and there the public health department kind of put out a search warrant to find me... A public health nurse comes around every two weeks to check up on me. It is not to do with me personally health wise. It is to do with the report, an act I have to follow (FG 4).

At the same time, a mode of governance organized through forms of subjectification associated with population-based risk management was suggested by our interviews. We heard many stories from people who were drug users, who were poor, or who suffered from mental illness, about having to do 'extra' healthwork as part of coming take HAART. These interview participants did not simply 'decide' to take medication, but had to demonstrate to health care providers their readiness and capacity to successfully manage complex drug regimens. In some instances, this involved bringing injection drug use under control, finding stable housing, or dealing with depression. Behind such forms of healthwork - treated as a precondition of access to treatment - stands professional suspicion that certain classes of people are unable to manage HAART regimens. For marginalized PHAs in our study, the social relations of compliance tie them to the institutional practices and discourses of social workers, counsellors, psychiatrists and other experts of subjectivity in the work of remaking the self and displaying life circumstances deemed necessary for successful pill-taking.

We view such forms of healthwork as continuous with a practice of the self that encourages individual PHAs to actively transform their lives and selves as part of responding to the compliance demands of a new biomedical treatment regimen. As the above examples suggest, however, self-governance is not always done under conditions of freedom; it is not an altogether liberal project. Self-governance can take varied social forms. Our research suggests how adherence can mobilize professional scrutiny and suspicion that fall disproportionately on marginalized PHAs.

Tensions between a population-based form of power that treats adherence as a property of particular social groups and a liberal form of governance that represents adherence as a desired project of any self are part of the field of current HIV/AIDS politics. Recent debates about access to HAART in Africa and other developing regions provide an important example of their operation. In 2001, the director of the United States Agency for International Development suggested that 'AIDS drugs' wouldn't work in Africa because many Africans don't use clocks and 'don't know what western time is” (McNeil, 2003). The director's remarks supported arguments against making HAART available to PHAs in developing regions on the public health grounds that their likely non-compliance would hasten the spread of drugresistant strains of HIV. His statements were met by outcry on the part of AIDS 
activists and have since been countered by research showing African PHAs to be just as, if not more, adherent to HAART regimens than their Western counterparts (Orrell et al., 2003).

Similar tensions take hold within the biomedical research literature on HAART and compliance in general. The most recent reviews of this literature consistently argue that sociodemographic variables such as race, gender, age, and income are poor predictors of adherence (Miller and Hays, 2000; Bartlett, 2002; Ammassari et al., 2002). As Wagner (2002, p. 600) notes 'for almost any studied variable, on can find a study in which the variable was correlated with adherence, and other studies that showed no such relationship.' Recent work further presents adherence as a 'dynamic phenomenon' involving 'several complexly related factors' (Miller and Hays, 2000, p. 177) and a potential problem for 'any patient' (Tsasis, 2001, p. 113). These reorientations continue in the midst of what appears to be an ongoing, if now minority, trajectory of inquiry within biomedicine committed to mining the relationship between adherence and sociodemographic characteristics (see for example Sharpe et al., 2004). This research has a primary stated goal of informing adherence strategies aimed at particular social groups. But to the extent that it mobilizes risk factor epidemiology, it continues to contribute to the construction of 'at-risk' marginalized social groups.

Recent contributors to the literature are well aware of and anxious about this problem. They are alert to how adherence research can be used to inform decisions about whom to treat and which 'high-risk' PHAs to support with scarce adherence-supporting resources (Wagner, 2002). As such they argue strenuously that adherence be understood as a complex phenomenon shaped by multiple, largely psychosocial factors. And they argue for 'lifestyle-tailored regimen[s]' (Chesney, 2003, p. 169) that meet the particular circumstances of individual patients. One can read these interventions as a corrective that wades into a complex terrain where older and newer representations of compliance/ adherence co-exist and where physicians continue to base treatment decisions on stereotypes of people's compliance capacities despite a consistent research base that argues against such sociodemographic risk profiling.

Given this reading of the literature, it would be a mistake to suggest that it projects an understanding of compliance/adherence as a form of medical dominance exercised over patients. The current literature does not blame PHAs for not following drug medications. It explicitly argues against treating PHAs as uninformed and, on the whole, has moved away from the population-based forms of risk profiling that have captured the imagination of social theorists of risk governance. Rather than treating marginalized groups as exemplars of non-compliance, the literature produces adherence as a mobile, and internally varied phenomenon, a complex behavioural and 
psychosocial field. According to Wright (2000, p. 704) there simply is no empirical evidence to support the claim by some clinicians that a 'typical' non-compliant patient exists. Non-adherence is no longer considered stabilized in particular high risk groups. In fact, recent contributions argue that homeless people, injection drug users, and ethnic and racial minorities can be just as adherent with medications as others (Wood et al., 2003; Bansberg et al., 2000).

According to the most recent contributions, then, anyone can be adherent or not, at different times, to different degrees, and for different and multiple psychosocial reasons. Within biomedical research, the risk of non-compliance is being detached from socioeconomic groups and democratized within a more or less shared psychic field. The newest work focuses primarily on variable health beliefs and attitudes including trust in health care providers, belief that medications will work and commitment to the pursuit of health, as a source of potentially modifiable factors that might influence adherence (Malcolm et al., 2003). Far from eschewing individual experience, biomedicine now reaches into the unique souls and lives of people in search of malleable terrain.

Current relations and conceptualizations of adherence to HAART are marked by forms of self governance that invite PHAs into an extended project of self-realization and management through new relationships to biomedical treatments. 'Find a regimen that you can live with' - 'one that fits who you are and how you live' a recent community-based health information resource advises (Project Inform, 2002, p. 2). 'You must feel ready', 'Keep a diary', 'do a check of your beliefs', consider 'your own feelings about anti-HIV drugs' (Pietrandoni, 2001; Poppa, 2003), 'Plan your future with VIRACEPT' (http://www.viracept.com/about.html) - these and other forms of advice offered through ASOs, pharmaceutical websites and other sources enter the individual lives of PHAs into the social technology of adherence. They encourage PHAs to consider and reflect on their lives - how they eat, their work schedules, whether they live alone, and so on - as both a resource and means of potential transformation to be used and worked through as part of an extended self and life project of taking pills well.

In our own research, PHAs rarely spoke about taking HAART in ways that emphasized physicians as sources of medical instruction they were to follow. They generally understood notions of ideal dosages as originating in a broader field of biomedical research and clinical experience. In differing ways and to varying degrees they were actively modifying their healthwork and making adjustments in their practices in ways that brought compliance goals into relation with parameters of flexibility and collective pill-taking strategies learned through associations with other PHAs. These ways of being suggest a 
politics of life and self that while socially 'stratified' (Clarke et al., 2003) invites anyone considering taking HAART to engage in concerns that bridge how they live and should live with the demands and promise of HAART regimens. Adherence to HAART is complex and not fully explained by relations of medical oppression. It involves a tension between a closure of adherence and its social proliferation as a psychosocial life practice. Multiple, intersecting, institutionally varied and conflicting forms of power are implicated.

\section{CONCLUSION}

Much has changed in the near three decades that have passed since the foundational social critique of compliance was first expressed. Important consumer-based health movements articulating new responsibilities, new demands, and new relationships to health care providers have flourished. Challenges to traditional welfare state functions have given rise to health policy and reform initiatives encouraging greater individual responsibility for health. Pharmaceutical drugs have become a part of our lives and health in ever present ways, increasingly shaping definitions of health problems and biomedical and popular responses to disease (Cohen et al., 2001). At the same time, the early social critique of compliance has made inroads in the health sciences. Corrective concepts such as Zola's 'therapeutic alliance' now have an active life within biomedical discourse and new definitions of adherence have all but replaced a concern with how well patients follow medical advice with how well they can 'self-manage a given illness' (http://www.apha.org/ ppp/hiv/\#). These developments call for a rethinking of the early social critique of medication compliance. Surprisingly that reassessment is still in its early stages (see Ferzacca, 2000; Race, 2003).

In this paper, we draw on the context of HIV/AIDS to explore new ways to think about how power is exercised through compliance. While our argument is tied to this empirical specificity, we suggest there may be parallels with diabetes and other chronic illnesses. As more and more people and more and more 'illnesses' are pulled into pharmaceutical relations, questions about responsible drug use will multiply.

In developing our argument, we have been guided by the analytic spirit of others who have undertaken the revision of established sociological approaches to the investigation of health phenomena. Throughout, our concern has been to critique responsibly - to recognize what is enduring of the early social analysis of medication compliance - but also to move it forward and elsewhere on the basis of new empirical and theoretical developments. 
Overall, we have suggested a practice of sociological engagement with adherence that is less wedded to the goal of making adherent subjects and that breaks from a critique of anti-humanist medical power. We have wanted to foreground the limits of understanding compliance/adherence as an expression of excessive medical authority that overrides the world of patient experience. In its place we present compliance/adherence as a terrain of different interacting forms of power. Our analysis is based on combining the theoretical insights of Smith and Foucault with empirical investigation of the healthwork of PHAs. Smith offers a way of thinking about 'experience' including experiences of taking pills - as the ongoing activities of actual people, always situated within extended institutional and discursive relations. Recent theorizing within the Foucauldian corpus emphasizes the simultaneity of various forms of power: sovereign, disciplinary, biopolitical, liberal selfgoverning (Weir, 2004). Drawing these lines of analysis together, compliance/ adherence lifts off the pages of the research texts of biomedicine and can be explored as a social technology - a complex of representations, forms of advice, strategies and knowledge - that is constitutive of experience and that traverses biomedical authority, population-based forms of risk governance and liberal techniques of the self.

Our destablization of the sociological model of medical dominance in the sociological analysis of medication compliance should not be taken as support for a liberal conception of medicine. Nor is it a matter of dissolving earlier theoretical commitments 'in a warm bath of pluralities, mobilities and differences' (Williams, 2003, p. 135). In our view, attending carefully to the contemporary social relations of power in adherence involves sharpening sociology's critical imagination. It means wading into the intersecting streams of power implicated in adherence and abandoning the comfort of old sociological targets to better read and respond to the complexity of the present.

\section{Acknowledgements}

The research upon which this paper is based was funded by the Positive Action Program, AIDS Program Committee, Ontario Ministry of Health. An earlier version of the paper was presented at the Vital Politics Conference, LSE in September 2003.

\section{ENDNOTES}

1 In this article we do not identify every quoted speaker by gender, race, class, sexual orientation, manner of acquiring HIV or number of years since HIV diagnosis. It is not the intent of the analysis pursued here to explain people's views on medication or their practices of adherence by locating these as arising in particular life experiences or social locations. We are also uncomfortable with the way labels such as 'black middle-class man' can work to imply that class, race and gender are individual characteristics rather than social relations. In our research we found that people's work of 
looking after their health with HIV was shaped by many things, and these circumstances are not easily summarized in common identity labels applied across the board to all quoted informants. Therefore, we have chosen only to identify which interview or focus group a particular excerpt is from. Where it is relevant to the immediate discussion, we do provide contextualizing information about the social location and life circumstances of the quoted speakers.

2 Writing in the health sciences literature Chesney et al. (2000), Miller and Hays (2000) and others present the concept of adherence as a corrective to earlier compliance-based approaches that blamed patients for not following physicians' guidelines. Our own fieldwork complicates this simple conceptual distinction and poses difficult questions about the relationship between 'official' and 'on the ground' uses of the terms and the precise relationship between the concepts. In our interviews and analysis of current pharmaceutical and community-based texts, we found both terms used widely and compliance used without the earlier negative connotations. Often compliance and adherence were used interchangeably to refer to how well a PHA's medication practices approximate a medical ideal. At the same time, we recognize that adherence is now the dominant biomedical concept. To reflect the complexity of these conditions of discourse use, we have adopted the following strategy. Throughout the paper, we hold to the original usage when citing published papers or original interview material. For example, we stress that the original social critique was a critique of compliance not adherence. However, when referring to current practices and relations of medication use we introduce the term compliance/adherence and also alternate between compliance and adherence. In our view this strategy responds to how the term adherence helps to discursively coordinate new relations of power which are the central object of the paper, but also reflects how the concept compliance has been folded into those relations in contemporary language use.

3 Healthwork is a more empirically expansive concept than medication practice. In this study we understood healthwork to include research participants' dealings with physicians and other health care providers, their work of coming to take treatments, of using health information and of managing medications, as well as their efforts to negotiate the economic, social and emotional consequences of chronic illness.

\section{ABOUT THE AUTHORS}

Eric Mykhalovskiy is an assistant professor in the department of Sociology, York University. His research focuses on the social organization of knowledge in health care. Recent work on evidencebased medicine and on HIV/AIDS has been published in various international journals.

Liza McCoy is assistant professor of sociology at the University of Calgary. Her research interest is in the social organization of knowledge, which she has been exploring through empirical studies in the fields of health, employment and immigration.

Michael Bresalier is completing a PhD at the Department of the History and Philosophy of Science, University of Cambridge. His current research is in the history of biomedicine, with particular emphasis on the material culture, organization and interaction of laboratory, clinical and public health practices in shaping the identity of virus diseases.

\section{REFERENCES}

Ammassari A, Trotta MP, Murri R, Castelli F, Narciso P, Noto P, Vecchiet J, D’Arminio Monforte A, Wu Aw, Antinori A, AdiCoNA Study Group (2002). Correlates and predictors of adherence to highly active antiretroviral therapy: overview of published literature. Journal of Acquired Immune Deficiency Syndromes 31: S123-S127. 
Bartlett JA (2002). Addressing the challenges of adherence. Journal of Acquired Immune Deficiency Syndromes 29: S2-S10.

Bansberg DR, Hecht FM, Charlebois ED, Zolopa AR, Holodniy M, Sheiner L, Bamberger JD, Chesney MA, Moss A (2000). Adherence to protease inhibitors, HIV-1 viral load, and development of drug resistance in an indigent population. AIDS 14: 357-366.

Bristol-Myers Squibb (ed) (2004). Bristol-Myers Squibb Virology. Hp. 2004. [copyright]. Online. Available: http://www.bmsvirology.com/managehiv. Accessed 27/04/2004.

Burchell G, Gordon C, Miller P (eds) (1991). The Foucault Effect: Studies in Governmentality. University of Chicago Press: Chicago.

Campbell M, Copeland B, Tate B (1998). Taking the standpoint of people with disabilities in research: experiences with participation. Canadian Journal of Rehabilitation 12: 95-104.

Chesney MA (2003). Adherence to HAART regimens. AIDS Patient Care and STDs 17: 169-177.

Chesney MA, Morin M, Sherr L (2000). Adherence to HIV combination therapy. Social Science \& Medicine 50: 1599-1605.

Chewning B, Sleath B (1996). Medication decision-making and management: a client-centred model. Social Science \& Medicine 42: 389-398.

Clarke AE, Mamo L, Fishman JR, Shim JK, Foskett JR (2003). Biomedicalization: technoscientific transformations of health, illness, and U.S. biomedicine. American Sociological Review 68: 161-194.

Cohen D, McCubbin M, Collin J, Pérodeau G (2001). Medications as social phenomena. Health 54: 441-469.

Conrad P (1985). The meaning of medications: another look at compliance. Social Science \& Medicine 20: 29-37.

Corbin J, Strauss A (1985). Managing chronic illness at home: three lines of work. Qualitative Sociology 8: 224-247.

Corbin J, Strauss A (1988). Unending Work and Care: Managing Chronic Illness at Home. Jossey-Bass: San Francisco, CA.

Cox LE (2002). Social support, medication compliance and HIV/AIDS. Social Work in Health Care 35: $425-460$.

Crawford R (1994). The boundaries of the self and the unhealthy other: reflections on health, culture and AIDS. Social Science \& Medicine 38: 1347-1365.

Cruikshank B (1999). The Will to Empower: Democratic Citizens and Other Subjects. Cornell University Press: Ithaca, NY.

Dilorio C, Resnicow K, McDonnell M, Soet J, McCarty F, Yeager K (2003). Using motivational interviewing to promote adherenct ot antiretroviral medications: a pilot study. Journal of the Association of Nurses in AIDS Care 14: 52-62.

Donovan JL, Blake DR (1992). Patient non-compliance: deviance or reasoned decision-making. Social Science \& Medicine 34: 507-513.

Ferzacca S (2000). 'Actually, I don't feel that bad': managing diabetes and the clinical encounter. Medical Anthropology Quarterly 14: 28-50.

Foucault M (1980a [1976]). The History of Sexuality. Volume 1: An Introduction. Vintage Books: New York.

Foucault M (1980b [1976]). The politics of health in the eighteenth century. In: Gordon C (ed). Power/Knowledge: Selected Interviews and Other Writings 1972-1977 by Michel Foucault. Pantheon Books: New York. pp 166-182.

Foucault M (1994 [1963]). Birth of the Clinic: An Archaeology of Medical Perception. Vintage Books: New York.

Haynes RB (1979a). Determinants of compliance: the disease and the mechanics of treatment. In: Haynes RB, Taylor DW, Sackett DL (eds). Compliance in Health Care. Johns Hopkins University Press: Baltimore, MD. pp 49-62. 
Haynes RB (1979b). Introduction. In: Haynes RB, Taylor DW, Sackett DL (eds). Compliance in Health Care. Johns Hopkins University Press: Baltimore, MD. pp 1-7.

Haynes RB, Taylor DW, Sackett DL (eds) (1979). Compliance in Health Care. Johns Hopkins University Press: Baltimore, MD.

Highleyman L (2000). Adverse effects associated with antiretroviral therapy. Bulletin of Experimental Treatment for AIDS 13: 23-31.

Holzemer WL, Henry SB, Portillo CJ, Miramontes H (2000). The client adherence profilingintervention tailoring (CAPT-IT) intervention for enhancing adherence to HIV/AIDS medications: a pilot study. Journal of the Association of Nurses in AIDS Care 11: 36-44.

Hulka BS (1979). Patient-clinician interactions and compliance. In: Haynes RB, Taylor DW, Sackett DL (eds). Compliance in health care. Johns Hopkins University Press: Baltimore, MD. pp 63-77.

Hunt LM, Arar NH (2001). An analytical framework for contrasting patient and provider vies of the process of chronic disease management. Medical Anthropology Quarterly 15: 347-367.

Hunt LM, Jordan B, Irwin S, Browner CH (1989). Compliance and the patient's perspective: controlling symptoms in everyday life. Culture, Medicine and Psychiatry 13: 315-334.

Lerner BH (1996). Public health then and now: temporarily detained: tuberculous alcoholics in Seattle, 1949 through 1960. American Journal of Public Health 86: 257-265.

Lerner BH (1997). From careless consumptives to recalcitrant patients: the historical construction of non-compliance. Social Science \& Medicine 45: 1423-1431.

Lerner BH, Gulick RM, Neveloff Dubler N (1998). Rethinking nonadherence: historical perspectives on triple-drug therapy for HIV disease. Annals of Internal Medicine 129: 573-578.

Linsk NL, Keigher SM (1997). Of magic bullets and social justice: emerging challenges of recent advances in AIDS treatment. Health and Social Work 22: 70-74.

Löwy I (1996). Between Bench and Bedside: Science, Healing, and Interleukin-2 in a Cancer Ward. Harvard University Press: Cambridge, MA.

Making Care Visible Project Team (Bresalier M, Gillis L, McClure C, McCoy L, Mykhalovskiy E, Taylor D, Webber M) (2002). Making Care Visible: Antiretroviral Therapy and the Healthwork of People Living with HIV/AIDS. A research report funded by the Positive Action Program, administered by the AIDS Bureau, Ontario Ministry of Health.

Malcolm SE, Ng JJ, Rosen RK, Stone VE (2003). An examination of HIV/AIDS patients who have excellent adherence to HAART. AIDS Care 15: 251-261.

McNeil Jr DG (2003). Africans outdo Americans in following AIDS therapy. New York. Times, 3 September.

Miller LG, Hays RD (2000). Adherence to combination antiretroviral therapy: synthesis of the literature and clinical implications. The AIDS Reader 10: 177-185.

Miller P, Rose N (1990). Governing economic life. Economy and Society 19: 1-31.

Mol A (2002). The Body Multiple: Ontology in Medical Practice. Duke University Press: Durham and London.

Mol A, Berg M (eds) (1998). Differences in Medicine: Unravelling Practices, Techniques, and Bodies. Duke University Press: Durham and London.

Moore A, Candlin CN, Plum GA (2001). Making sense of HIV-related viral load: one expert or two? Culture, Health \& Sexuality 3: 429-450.

Mundy L, Kalluri P, Meredith K, Marshall L, Fraser VJ, Thompson P (2002). Women with HIV infection: a model of university-based care, training and research. AIDS Care 14: S95-S107.

Murphy EL, Collier AC, Kalish LA, Assmann SF, Para MF, Flanigan TP, Kumar PN, Mintz L, Wallach FR, Nemo GJ (2001). Highly active antiretroviral therapy decreases mortality and morbidity in patients with advanced HIV disease. Annals of Internal Medicine 135: 17-26.

Mykhalovskiy E (2003). Evidence-based medicine: Ambivalent reading and the clinical recontextualization of science. Health 7: 269-296. 
Mykhalovskiy E, McCoy L (2002). Troubling ruling discourses of health: using institutional ethnography in community-based research. Critical Public Health 12: 17-37.

Mykhalovskiy E, Weir L (2004). The problem of evidence-based medicine: directions for social science. Social Science and Medicine 59: 1059-1069.

Orrell C, Bangsberg DR, Badri M, Wood R (2003). Adherence is not a barrier to successful antiretroviral therapy in South Africa. AIDS 17: 1369-1375.

Osborne T (1994). On anti-medicine and clinical reason. In: Jones C, Porter R (eds). Reassessing Foucault: Power, Medicine, and the Body. Routledge: London.

Palella Jr FJ, Delaney KM, Moorman AC, Loveless MO, Fuhrer J, Satten GA, Aschman DJ, Holmberg SD (1998). Declining morbidity and mortality among patients with advanced human immunodeficiency virus infection. New England Journal of Medicine 338: 853-860.

Parsons T (1951). The Social System. Free Press: New York.

Paterson DL, Swindells S, Mohr J, Brewster M, Vergis EN, Squier C, Wagener MN, Singh N (2000). Adherence to protease inhibitor therapy and outcomes in patients with HIV infection. Annals of Internal Medicine 133: 21-30.

Pietrandoni G (2001) Adherence 101. Positively Aware 12: 30-31.

Poppa A (2003). Skills for treatment success.... Positive Nation 90. http://www.positivenation. co.uk/issue90/treatment/treatment1/treatment1.htm\#top

Project Inform (2002). Adherence: Keeping Up with your Meds. Project Inform: San Francisco.

Race K (2003). Prescribing the self. Paper presented at Vital Politics: Health, Medicine and Bioeconomics into the Twenty-first Century. London School of Economics. September 2003.

Rankin J (2001). Texts in action: how nurses are doing the fiscal work of health care reform. Studies in Cultures, Organizations and Societies 7: 251-267.

Rapp R (2000). Extra chromosomes and blue tulips: medico-familial interpretations. In: Lock M, Cambrosio A, Young A (eds). Living and Working with the New Medical Technologies: Intersections of Inquiry. Cambridge University Press: New York.

Root R, Brownher C (2001). Practices of the pregnant self: compliance with and resistance to prenatal norms. Culture, Medicine and Psychiatry 25: 195-223.

Rose N (1994). Expertise and the government of conduct. Studies in Laws Politics and Society 14: 359-397.

Rose N (1999). Powers of Freedom: Reframing Political Thought. Cambridge University Press: Cambridge.

Rose N (2001). The politics of life itself. Theory, Culture, and Society 18: 1-30.

Rosengarten M (2004). Consumer activism in the pharmacology of HIV. Body \& Society 10: 91-107.

Sackett DL, Haynes RB (eds) (1976). Compliance with Therapeutic Regimens. Johns Hopkins University Press: Baltimore, MD.

Senak M (1997). Predicting antiviral compliance: physicians' responsibilities vs. patients' rights. Journal of the International Association of Physicians in AIDS Care 3: 45-48.

Sharpe TT, Lee LM, Nakashima AK, Elam-Evans LD, Fleming PL (2004). Crack cocaine use and adherence to antiretroviral treatment among HIV-infected black women. Journal of Community Health 29: 117-127.

Smith D (1987). The Everyday World as Problematic: A Feminist Sociology. University of Toronto Press: Toronto.

Smith D (1990). The Conceptual Practices of Power: a Feminist Sociology of Knowledge. University of Toronto Press: Toronto.

Smith D (1999). Writing the Social: Critique, Theory, and Investigations. University of Toronto Press: Toronto.

Smith G (1995). Accessing treatments: managing the AIDS epidemic in Ontario. In: Campbell M, Manicom A (eds). Knowledge Experience, and Ruling Relations. University of Toronto Press: Toronto. pp 18-34. 
Sollitto S, Mehlman M, Youngner S, Lederman MM (2001). Should physicians withhold highly active antiretroviral therapies from HIV-AIDS patients who are thought to be poorly adherent to treatment? AIDS 15: 153-159.

Stimson GV (1974). Obeying doctor's orders: a view from the other side. Social Science \& Medicine 8: 97-104.

Strong P (1979). Sociological imperialism and the profession of medicine: a critical examination of the thesis of medical imperialism. Social Science \& Medicine 13A: 199-215.

Trostle JA (1988). Medical compliance as an ideology. Social Science \& Medicine 27: 1299-1308.

Trostle JA, Hauser WA, Susser IS (1983). The logic of non-compliance: management of epilepsy from the patient's point of view. Culture, Medicine and Psychiatry 7: 35-56.

Tsasis P (2001). Adherence assessment to highly active antiretroviral therapy. AIDS Patient Care and STDs 15: 109-115.

Volberding PA (2003). HIV therapy in 2003: consensus and controversy. AIDS 17: S4-S11.

Wagner GJ (2002). Predictors of antiretroviral adherence as measured by self-report, electronic monitoring, and medication diaries. AIDS Patient Care and STDs 16: 599-608.

Wainberg M, Friedland G (1998). Public health implications of antiretroviral therapy and HIV drug resistance. Journal of the American Medical Association 279: 1977-1983.

Weir L (2004). On the Threshold of the Living Subject: Pregnancy, Risk and Vital Politics. Book manuscript under review.

Williams GH (2003). The determinants of health: structure, context and agency. Sociology of Health and Illness 25: 131-154.

Wood E, Montaner J, Bangsberg DR, Tyndall MW, Strathdee SA, O'Shaughnessy MV, Hogg RS (2003). Expanding access to HIV antiretroviral therapy among marginalized populations in the developed world. AIDS 17: 2419-2427.

Wright MT (2000) The old problem of adherence: research on treatment adherence and its relevance for HIV/AIDS. AIDS Care 12: 703-710.

Wynn GH, Zapor MJ, Smith BH, Wortmann G, Oesterheld JR, Armstrong SC, Cozza KL (2004). Antiretrovirals, part 1: overview, history, and focus on protease inhibitors. Psychosomatics 45 : 262-270.

Zola I (1981). Structural constraints in the doctor-patient relationship: the case of non-compliance. In: Eisenberg L, Kleinman A (eds). The Relevance of Social Science for Medicine. D. Reidel Publishing: Boston, MA. pp 241-252. 
Reproduced with permission of the copyright owner. Further reproduction prohibited without permission. 